\title{
Hypoxemia and Reoxygenation with $21 \%$ or $100 \%$ Oxygen in Newborn Pigs: Changes in Blood Pressure, Base Deficit, and Hypoxanthine and Brain Morphology
}

\author{
TERJE ROOTWELT, ELSE MARIT LØBERG, ATLE MOEN, STEPHANIE ØYASÆTER, AND \\ OLA DIDRIK SAUGSTAD \\ Institute for Surgical Research [T.R.] and Department of Pediatric Research [T.R., A.M., S.O., O.D.S.], \\ University of Oslo, Rikshospitalet, N-0027 Oslo 1; and Division of Neuropathology, Department of Pathology, \\ Ullevaal University Hospital, N-0407 Oslo 4, Norway
}

\begin{abstract}
To study whether room air is as effective as $100 \% \mathrm{O}_{2}$ in resuscitation after hypoxia, hypoxemia $\left(\mathrm{PaO}_{2}\right.$ 2.3-4.3 $\mathrm{kPa}$ ) was induced in newborn pigs (2-5 d old) by ventilation with $8 \% \mathrm{O}_{2}$ in nitrogen. When systolic blood pressure had fallen to $20 \mathrm{~mm} \mathrm{Hg}$, animals were randomly reoxygenated with either $21 \% \mathrm{O}_{2}$ (group $1, n=9$ ) or $100 \%$ $\mathrm{O}_{2}$ (group $2, n=11$ ) for $20 \mathrm{~min}$ followed by $21 \% \mathrm{O}_{2}$ in both groups. Controls (group $3, n=5$ ) were ventilated with $21 \% \mathrm{O}_{2}$ throughout the experiment. Base deficit peaked at $31 \pm 5 \mathrm{mmol} / \mathrm{L}$ (mean $\pm \mathrm{SD}$ ) for both hypoxic groups at 5 min of reoxygenation and then normalized over the following $3 \mathrm{~h}$. There were no statistically significant differences between the two groups during reoxygenation concerning blood pressure, heart rate, base deficit, or plasma hypoxanthine. Hypoxanthine peaked at $165 \pm 40$ and $143 \pm 42$ $\mu \mathrm{mol} / \mathrm{L}$ in group 1 and 2 (NS), respectively, and was eliminated monoexponentially in both groups with an initial half-life for excess hypoxanthine of $48 \pm 21$ and $51 \pm 27$ min (NS), respectively. Blinded pathologic examination of cerebral cortex, cerebellum, and hippocampus after $4 \mathrm{~d}$ showed no statistically significant differences with regard to brain damage. We conclude that $21 \% \mathrm{O}_{2}$ is as effective as $100 \% \mathrm{O}_{2}$ for normalizing blood pressure, heart rate, base deficit, and plasma hypoxanthine after severe neonatal hypoxemia in piglets and that the extent of the hypoxic brain damage is similar in the two groups. (Pediatr Res 32: 107-113, 1992)
\end{abstract}

\section{Abbreviations}

CSF, cerebrospinal fluid

$\mathrm{PaCO}_{2}$, arterial $\mathrm{CO}_{2}$ tension

$\mathrm{PaO}_{2}$, arterial $\mathrm{O}_{2}$ tension

The sudden reintroduction of oxygen to hypoxic tissues may result in a burst of oxygen free radical formation (1). Free radicals are highly reactive substances that can disturb the recovery of the hypoxic cells directly through lipid peroxidation of membranes and oxidation of proteins (2) or indirectly through de-

Received July 3, 1991; accepted February 17, 1992.

Correspondence and reprint requests: Dr. Terje Rootwelt, Department of Pediatric Research, University of Oslo, Rikshospitalet, N-0027 Oslo 1, Norway.

Supported by The Norwegian Women's Public Health Association, The Norwegian Research Council for Science and Humanities, Hans Homans Minde's Foundation, and Carl Semb's Foundation. Dr. Terje Rootwelt is a Research Fellow with the Norwegian Council on Cardiovascular Diseases. ranged postischemic microcirculation (3). Thus, there is concern that oxygen free radicals may increase the hypoxic tissue damage through a posthypoxic reoxygenation injury (4). The newborn brain may be particularly vulnerable to oxygen radical damage. It contains large amounts of polyunsaturated fatty acids susceptible to lipid peroxidation (2), and it has low levels of the antioxyenzyme catalase (5). Adult brain has a high level of the oxygen radical scavenger superoxide dismutase, but how much lower the level of this enzyme is in neonates is not clear (6-8).

Asphyxiated newborns are usually resuscitated with high concentrations of $\mathrm{O}_{2}$. The guidelines of the American Heart Association for resuscitation (9) recommend ventilation by bags that can give as close to $100 \% \mathrm{O}_{2}$ as possible. Milner (10) states that it is "... extremely unlikely that exposure to $100 \%$ oxygen for even 15 to $20 \mathrm{~min}$ is likely to have any long-term adverse effects." Intuitively, it seems reasonable to treat severe hypoxia with extra oxygen, but the necessity or possible adverse effects of this practice have not been thoroughly examined.

The present study tests whether or not oxygen supplementation is advantageous in the reoxygenation of the hypoxic newborn. Newborn pigs exposed to severe hypoxemia were randomized to reoxygenation with either $21 \%$ or $100 \% \mathrm{O}_{2}$. Acute recovery in the two groups was compared according to the normalization of blood pressure, heart rate, metabolic acidosis, and plasma hypoxanthine, a marker of tissue hypoxia $(11,12)$. After $4 \mathrm{~d}$, the extent of the hypoxic brain damage was evaluated by a blinded pathologic examination.

\section{MATERIALS AND METHODS}

Animal preparation. Newborn pigs (2-5 d old) were delivered from a local farmer on the day of the experiments. They were premedicated with azaperone (4 mg/kg intramuscularly), cannulated in a peripheral ear vein, and given atropine $(0.025 \mathrm{mg} /$ $\mathrm{kg}$ i.v.) and metomidate until adequate anesthesia was achieved (4-10 mg/kg i.v.). Muscle relaxation was then induced with pancuronium bromide $(0.2 \mathrm{mg} / \mathrm{kg}$ i.v. $)$. Additional metomidate $(4 \mathrm{mg} / \mathrm{kg}$ ) was given when necessary and atropine $(0.025 \mathrm{mg} / \mathrm{kg})$ was given every $2-3 \mathrm{~h}$. The pigs were intubated with a $3.0-\mathrm{mm}$ cuffed Sheridan endotracheal tube. The tube was connected via a small humidifier (Portex Termovent 600) to a Servo 900 B ventilator (Elema-Schønander, Stockholm, Sweden). The pigs were mechanically ventilated at 40 breaths $/ \mathrm{min}$. Tidal volume was adjusted when necessary throughout the experiment to maintain $\mathrm{PaCO}_{2}$ between 4.6 and $5.9 \mathrm{kPa}$. Before hypoxemia, the pigs were ventilated with $21 \% \mathrm{O}_{2}$, and only pigs with $\mathrm{PaO}_{2}>9.3 \mathrm{kPa}$ were included. The rectal temperature was monitored continuously and kept between 38.0 and $39.5^{\circ} \mathrm{C}$ with a heating blanket 
and when necessary a heating lamp. An arterial catheter was inserted proximally from a superficial artery on the inside of the hind leg so that ischemia of the leg was avoided. The catheter was connected to a strain gauge transducer, Gould Recorder 2600S (Gould Inc. Recording Systems, Cleveland, OH), for continuous blood pressure recordings. The pulse was monitored continuously via skin electrodes. The pigs were placed on their sides and allowed to stabilize for $30 \mathrm{~min}$. During the experiments, a peripheral i.v. infusion containing $0.7 \% \mathrm{NaCl}$ and $1.25 \%$ glucose was given at a rate of $10 \mathrm{~mL} / \mathrm{kg} / \mathrm{h}$. Blood glucose was measured regularly with a reflectometer (Hypocount MX B; Boehringer, Mannheim, Germany), and the infusion was altered as necessary to maintain glucose between 4 and $10 \mathrm{mmol} / \mathrm{L}$.

Experimental protocol. The piglets were randomly assigned to control or hypoxemia groups. Animals allocated to the hypoxemia group were ventilated with $8 \% \mathrm{O}_{2}$ in nitrogen. The $\mathrm{O}_{2}$ content of the inspired air was monitored with a Dameca OM 831 Oxygen Monitor (Dameca Inc., Copenhagen, Denmark). Hypoxemia was continued until systolic blood pressure fell to 20 $\mathrm{mm} \mathrm{Hg}$ or, in two animals (one from each group), until heart rate suddenly fell below 80 . The time when this happened could quite easily be determined with a $<1$ - to 2-min error margin. Animals were then randomized to reoxygenation with either $21 \%$ (group 1, $n=9$ ) or $100 \%$ (group $2, n=11$ ) $\mathrm{O}_{2}$ for $20 \mathrm{~min}$ followed by ventilation with $21 \% \mathrm{O}_{2}$ for both groups for a total of $180 \mathrm{~min}$ after reoxygenation. This randomization was performed before the experiment, but the investigator who decided when resuscitation should start (always the same person) was not informed until this decision was made. Blood and CSF samples were then taken, and the reoxygenation was started after 1 min. Four pigs suffered sudden asystolia before reoxygenation was started; none of them could be resuscitated, and they were excluded (three were randomized to room air and one to $100 \%$ oxygen). Control animals (group $3, n=5$ ) were ventilated with $21 \% \mathrm{O}_{2}$ for $5 \mathrm{~h}$.

Blood samples. Arterial blood samples were taken before hypoxemia, after $15 \mathrm{~min}$, and then every $30 \mathrm{~min}$ throughout hypoxemia. Additional samples were taken just before reoxygenation, after 5 and $15 \mathrm{~min}$, and then every $30 \mathrm{~min}$ for $3 \mathrm{~h}$. Temperature-corrected blood gases were measured with an AVL 945 Automatic Blood Gas System (AVL Biomedical Instruments, Schaffhausen, Switzerland). Blood for hypoxanthine analysis was collected into prechilled EDTA tubes and centrifuged without delay for $10 \mathrm{~min}$ at $1800 \times \mathrm{g}, 4^{\circ} \mathrm{C}$. Plasma was transferred to polypropylene tubes and frozen at $-20^{\circ} \mathrm{C}$ until analysis. The withdrawn blood was replaced with an equal volume of sterile $\mathrm{NaCl}(0.9 \%)$ and the catheter flushed with heparinized saline $(4 \mathrm{U} / \mathrm{mL})$.

Sampling of CSF. A lumbar puncture needle $(40 \times 0.7 \mathrm{~mm})$ was placed in the spinal canal at the level of the iliac crest just before hypoxemia. Samples of CSF (300-400 $\mu \mathrm{L})$ were collected every $30 \mathrm{~min}$ into polypropylene tubes as long as the needle was patent and were frozen at $-20^{\circ} \mathrm{C}$ for later analysis.

Care of animals. After 180 min of reoxygenation, the animals were allowed to wake up. They were taken off the ventilator when spontaneous breathing was adequate and extubated when sufficiently awake (3-10 h after hypoxia). The arterial catheter was kept until after extubation to monitor blood gases and blood pressures.

The animals were then returned to a cage with a heating blanket and hay. They were given piglet mother's milk substitute (Babylactal, Petter Möller A/S, Oslo, Norway) six to seven times daily. If they did not eat adequately by themselves, they were fed by gavage. Ampicillin $25 \mathrm{mg}$ was given i.v. at $180 \mathrm{~min}$ of reoxygenation and later once daily intramuscularly. Three animals (one from group 1 and two from group 2) suffered an additional insult after the $180 \mathrm{~min}$ of reoxygenation (hemorrhage, mucus plugging of the tube, and aspiration). These animals were excluded from the pathologic analysis.

In situ fixation. Four d after hypoxia, the animals were anes- thetized with pentobarbital $(15 \mathrm{mg} / \mathrm{kg}$ i.p. followed by $25 \mathrm{mg}$ i.v.). The trachea was cannulated, and the animal artificially ventilated with room air. Samples were taken from arterial blood, urine, CSF, and vitreous humor (using an empty Vacutainer (Becton, Dickinson and Company, Rutherford, NJ) and puncturing the eye $6 \mathrm{~mm}$ behind the limbus cornea). Additional pentobarbital $(20 \mathrm{mg} / \mathrm{kg})$ was given i.v. Through a thoracotomy, the upper body was rapidly flushed with isotonic saline until clear fluid came from the right atrium. The perfusion fluid was then changed to $4 \%$ phosphate buffered formaldehyde, which was continued for a total of $30 \mathrm{~min}$. The brain and the heart were then removed and placed in $4 \%$ buffered formaldehyde.

Analysis of hypoxanthine. Hypoxanthine was analyzed using an HPLC method $(13,14)$ with modifications as previously described (15).

Pathologic examination. Blocks from the frontal and parietal cortex, hippocampus, thalamus, basal ganglia, cerebellum, pons, and medulla oblongata were embedded in paraffin. Four- $\mu \mathrm{m}$ thick sections were stained with hematoxylin and eosin. The sections from the basal ganglia were also stained with the Luxol fast blue method for myelin and the Bodian method for axons. Paraffin sections from the hearts were studied in eight animals, four cases with severe cerebral lesions and four normal controls. Two transverse sections from each heart were stained with hematoxylin and eosin.

The pathologic study was performed on randomized slides with covered labels. The hypoxic/ischemic lesions in the cerebral cortex, the CA1 hippocampal area, and the cerebellum were graded from 0 to 3 as follows: Cortex: 1 , small $(\leq 1 \mathrm{~mm})$ infarcts in white matter; 2 , larger infarcts (4-6 mm) essentially in white matter; 3, large infarcts $(\geq 1 \mathrm{~cm})$ in cortex and white matter. Hippocampus CA $1: 1, \leq 30 \%$ necrotic neurons; $2,30-60 \%$ necrotic neurons; $3, \geq 60 \%$ necrotic neurons. Cerebellum: $1,0.1-$ $1 \%$ necrotic Purkinje cells in two sections; $2,1-2 \%$ necrotic Purkinje cells; $3,>10 \%$ necrotic Purkinje cells.

Statistics. Values are given as mean \pm SD. Comparisons between groups of repeated measurements were done with a multivariate analysis of variance test. Single parameters were compared using $t$ test or within groups with paired $t$ test. Pathologic scores were compared using the Mann-Whitney $U$ test. Analyses were performed with a SPSS/PC+ statistical package (SPSS Inc., Chicago, IL). Two-sided $p$ values $<0.05$ were considered significant.

Approval. The experimental protocols were approved by the hospital's ethics committee for animal studies.

\section{RESULTS}

There was considerable animal-to-animal variability in the duration of hypoxemia necessary to reduce systolic blood pressure to $20 \mathrm{~mm} \mathrm{Hg}$. However, the mean durations of hypoxemia in the two groups $[93 \pm 41 \mathrm{~min}$ (group 1) and $99 \pm 40 \mathrm{~min}$ (group 2)] were not statistically different. There were no statistically significant differences between the two hypoxic groups in any measured variable before or during hypoxia.

Blood gases. $\mathrm{PaO}_{2}$ levels (Fig. 1) were $3.4 \pm 0.5$ and $3.5 \pm 0.5$ $\mathrm{kPa}$ in group 1 and 2 , respectively, after $15 \mathrm{~min}$ of hypoxemia and rose to $5.2 \pm 0.9$ and $5.1 \pm 0.7 \mathrm{kPa}$ at the end of hypoxemia ( $p<0.001$ end of hypoxemia versus $15 \mathrm{~min}$ of hypoxemia for both groups). At $5 \mathrm{~min}$ of reoxygenation, group $1\left(21 \% \mathrm{O}_{2}\right.$ group $)$ had a mean $\mathrm{PaO}_{2}$ of $11.6 \pm 1.1 \mathrm{kPa}$, whereas in group $2(100 \%$ $\mathrm{O}_{2}$ group) $\mathrm{PaO}_{2}$ was $63.7 \pm 9.4 \mathrm{kPa}(p<0.001)$.

Repeated measures analysis from $30 \mathrm{~min}$ of reoxygenation and onward showed that group 2 was better oxygenated than group 1 even when both groups received room air $(p=0.03)$. This was mainly due to a higher $\mathrm{PaO}_{2}$ at 30 and $60 \mathrm{~min}$ (13.7 \pm 1.9 versus $11.3 \pm 1.9$ and $12.4 \pm 1.9$ versus $10.9 \pm 1.2 \mathrm{kPa}$ ). Later, the differences were small (Fig. 1). Excluding the period of hyperoxia, there were no statistically significant differences 


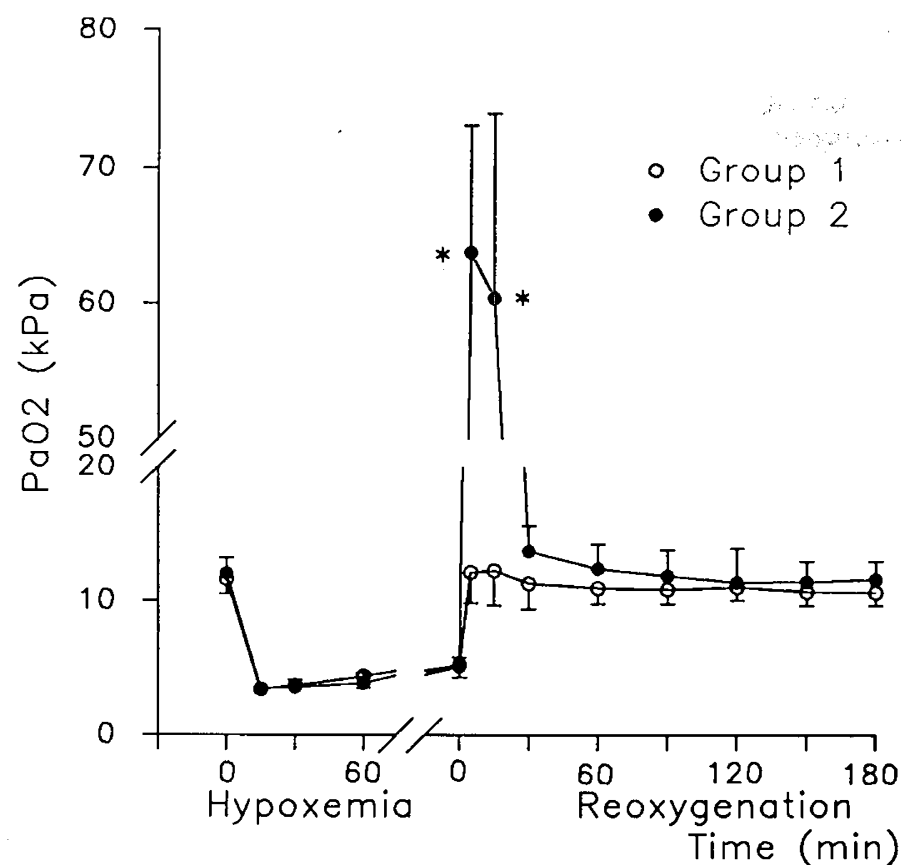

Fig. 1. $\mathrm{PaO}_{2}$ during hypoxemia and reoxygenation. Group 1 was reoxygenated with $21 \% \mathrm{O}_{2}$ and group 2 with $100 \% \mathrm{O}_{2}$. Values shown are mean $\pm \mathrm{SD} .{ }^{*}, p<0.001$ group 1 vs group 2 . Repeated measures analysis from $30 \mathrm{~min}$ of reoxygenation and later for group $1 \mathrm{vs}$ group 2 yields $p<0.05$.

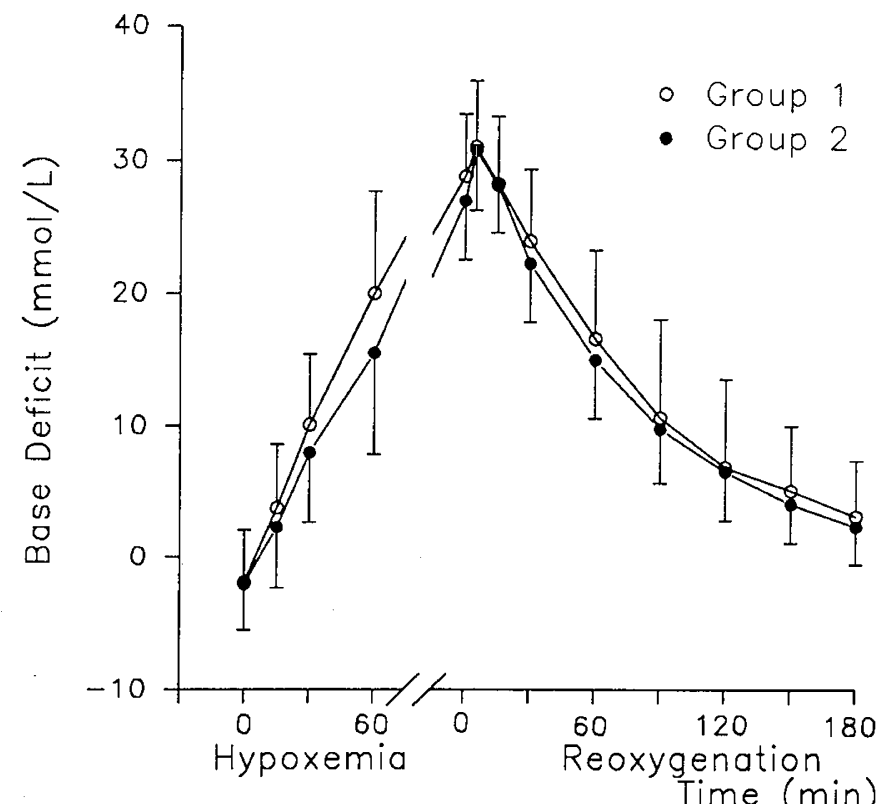

Fig. 2. Base deficit during hypoxemia and reoxygenation. Group was reoxygenated with $21 \% \mathrm{O}_{2}$ and group 2 with $100 \% \mathrm{O}_{2}$. Values shown are mean $\pm \mathrm{SD}$

between the values before and after hypoxemia for each group separately.

Base deficit (Fig. 2) reached $29 \pm 5$ and $27 \pm 4 \mathrm{mmol} / \mathrm{L}$ in group 1 and 2 , respectively, at the end of hypoxemia and increased in all animals during the first $5 \mathrm{~min}$ of reoxygenation to a mean peak of $31 \pm 5 \mathrm{mmol} / \mathrm{L}$ for both groups. Base deficit then steadily fell and was normalized for both groups after 180 min with no significant differences between the two groups.

Table 1 shows $\mathrm{pH}$ and $\mathrm{PaCO}_{2}$ at selected times. The $\mathrm{pH}$ levels fell to minimum values at $5 \mathrm{~min}$ of reoxygenation $(6.75 \pm 0.14$ and $6.76 \pm 0.13$ in group 1 and 2 , respectively). There were no
Table 1. $\mathrm{PaCO}_{2}, \mathrm{pH}$, and blood glucose (B-Glu) during hypoxemia and reoxygenation*

\begin{tabular}{|c|c|c|c|c|c|}
\hline \multirow{2}{*}{\multicolumn{2}{|c|}{ Group }} & \multicolumn{2}{|c|}{ Hypoxemia } & \multicolumn{2}{|c|}{ Reoxygenation } \\
\hline & & Before & End & $30 \mathrm{~min}$ & $180 \mathrm{~min}$ \\
\hline \multirow{2}{*}{$\begin{array}{c}\mathrm{PaCO}_{2} \\
\quad(\mathrm{kPa})\end{array}$} & 1 & $5.3 \pm 0.7$ & $4.1 \pm 0.6$ & $5.4 \pm 0.5$ & $5.5 \pm 0.7$ \\
\hline & 2 & $5.0 \pm 0.5$ & & $5.1 \pm 0.7$ & $5.3 \pm 0.6$ \\
\hline \multirow[t]{2}{*}{$\mathrm{pH}$} & 1 & $7.42 \pm 0.07$ & $6.81 \pm 0.13$ & $6.93 \pm 0.15$ & $7.34 \pm 0.06$ \\
\hline & 2 & $7.44 \pm 0.06$ & $6.84 \pm 0.12$ & $6.98 \pm 0.10$ & $7.36 \pm 0.05$ \\
\hline \multirow{2}{*}{$\begin{array}{l}\text { B-Glu } \\
\text { (mM) }\end{array}$} & 1 & $5.6 \pm 1.3$ & $12.0 \pm 8.3$ & $9.9 \pm 5.7$ & $6.3 \pm 2.5$ \\
\hline & 2 & $6.4 \pm 1.5$ & $9.5 \pm 5.9$ & $8.0 \pm 4.8$ & $5.2 \pm 1.5$ \\
\hline
\end{tabular}

* Group $1(n=9)$ was reoxygenated with $21 \% \mathrm{O}_{2}$, and group $2(n=$ 11) was reoxygenated with $100 \% \mathrm{O}_{2}$. Values shown are mean $\pm \mathrm{SD}$.

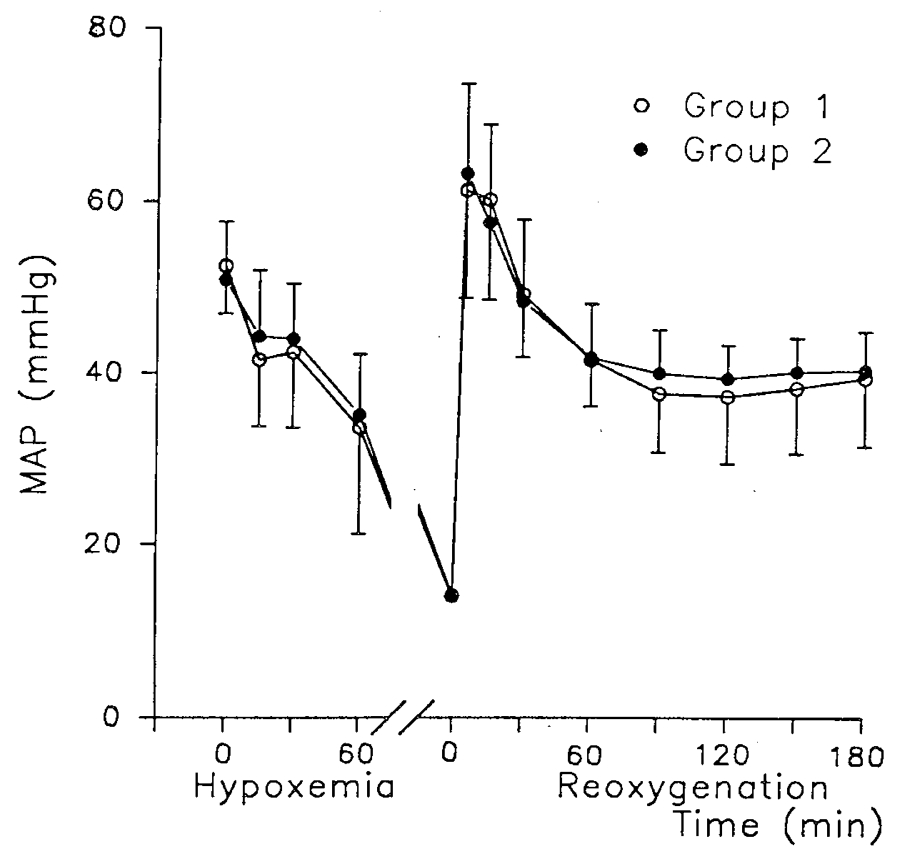

Fig. 3. Mean arterial blood pressure (MAP) during hypoxemia and reoxygenation. Group 1 was reoxygenated with $21 \% \mathrm{O}_{2}$ and group 2 with $100 \% \mathrm{O}_{2}$. Values shown are mean $\pm \mathrm{SD}$. MAP at reoxygenation was estimated to be $14 \mathrm{~mm} \mathrm{Hg}$ for both groups.

statistically significant differences between the two groups in $\mathrm{pH}$, $\mathrm{PCO}_{2}$, or temperature throughout the experiments.

Blood pressure. Mean blood pressure (Fig. 3) was $52 \pm 6$ and $51 \pm 7 \mathrm{~mm} \mathrm{Hg}$ in group 1 and 2, respectively, before hypoxemia. After $5 \mathrm{~min}$ of reoxygenation, mean pressure had risen to $61 \pm$ 13 and $63 \pm 10 \mathrm{~mm} \mathrm{Hg}(p<0.05$ versus before hypoxemia for both groups). Blood pressure slowly fell to $42 \pm 5$ and $42 \pm 6$ $\mathrm{mm} \mathrm{Hg}$ in the two groups after $60 \mathrm{~min}$ of reoxygenation ( $p<$ 0.001 versus before hypoxemia for both groups) and then stabilized. There were no statistically significant differences in blood pressure between the two groups at any time.

Heart rate. Heart rate (Fig. 4) rose slightly after hypoxemia was initiated and did not fall markedly until the last minutes before reoxygenation. Heart rate was normalized after $5 \mathrm{~min}$ of reoxygenation in both groups. After $30 \mathrm{~min}$, heart rate was somewhat higher in group 1, although this did not reach statistical significance $(p=0.06)$.

Plasma hypoxanthine. Plasma hypoxanthine (Fig. 5) rose from baseline levels of $31 \pm 6$ and $28 \pm 8 \mu \mathrm{mol} / \mathrm{L}$ to a maximum of $165 \pm 40$ and $143 \pm 42 \mu \mathrm{mol} / \mathrm{L}$ in the two groups at the end of hypoxemia ( $p<0.001$ versus before hypoxemia for both groups, NS group 1 versus group 2). Already 5 min after the cessation of hypoxemia, hypoxanthine was reduced in both groups. Hypoxanthine was eliminated monoexponentially with similar rates in the two groups. Least square fit calculation for the first 15 


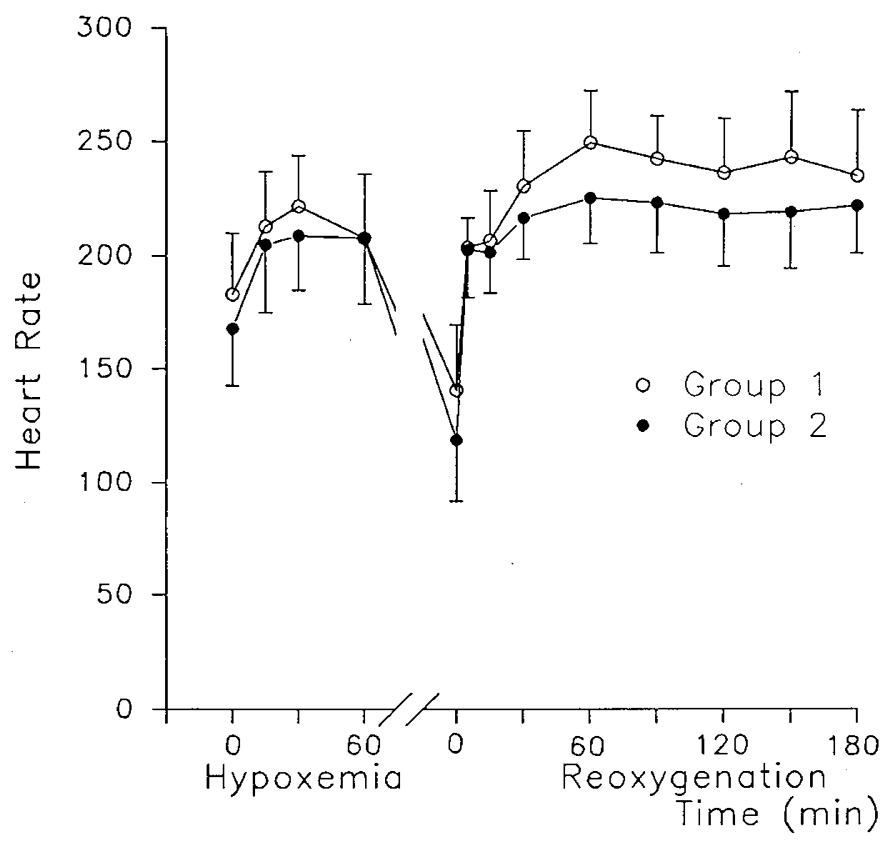

Fig. 4. Heart rate during hypoxemia and reoxygenation. Group 1 was reoxygenated with $21 \% \mathrm{O}_{2}$ and group 2 with $100 \% \mathrm{O}_{2}$. Values shown are mean $\pm \mathrm{SD}$.

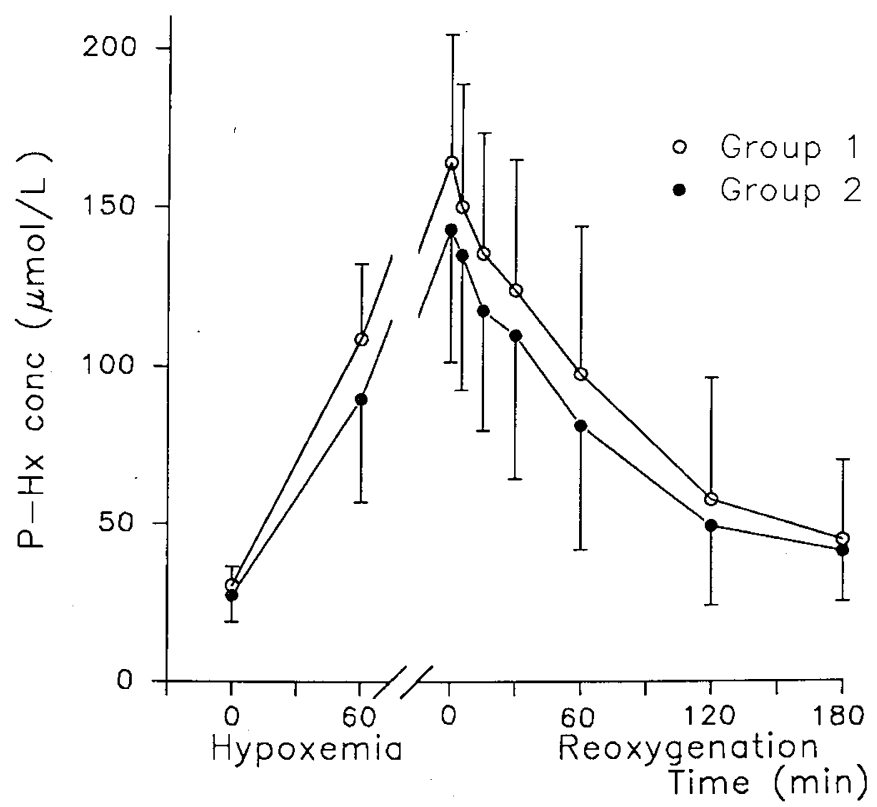

Fig. 5. Plasma hypoxanthine concentrations $(P-H x)$ during hypoxemia and reoxygenation. Group 1 was reoxygenated with $21 \% \mathrm{O}_{2}$ and group 2 with $100 \% \mathrm{O}_{2}$. Values shown are mean $\pm \mathrm{SD}$.

min of reoxygenation gave a half-life of excess hypoxanthine [i.e. absolute value minus prehypoxemic value (16)] of $48 \pm 21$ and $51 \pm 27 \mathrm{~min}$ in group 1 and 2 (NS), respectively. For the whole reoxygenation period, half-life was $55 \pm 30$ and $54 \pm 21 \mathrm{~min}$ (NS), respectively.

CSF hypoxanthine. During hypoxemia, CSF hypoxanthine rose from $23 \pm 7$ and $21 \pm 8 \mu \mathrm{mol} / \mathrm{L}$ in group 1 and 2 , respectively, to $78 \pm 26$ and $66 \pm 25 \mu \mathrm{mol} / \mathrm{L}$ (NS group 1 versus group $2, p<0.005$ versus before hypoxemia for both groups). Due to technical difficulties, only seven piglets had CSF hypoxanthine measured at all times during reoxygenation. In contrast to plasma hypoxanthine, CSF hypoxanthine did not start to fall until after $30-60 \mathrm{~min}$ of reoxygenation in six of seven piglets. After $180 \mathrm{~min}$, hypoxanthine levels were normalized. Due to the small numbers, comparisons between the two groups were not made.

Blood glucose and hematocrit. The piglets reacted somewhat differently to hypoxemia with regard to blood glucose homeostasis (Table 1). Although the smallest piglets tended to become hypoglycemic (a condition that was corrected with 5\% glucose), most animals reacted with hyperglycemia despite a change to a glucose-free infusion. Blood glucose normalized after 30-120 min of reoxygenation, and there were no significant differences between the two groups. The piglets had a marked physiologic anemia compared to human babies. Mean hematocrit levels were 24-26\% with no significant differences between the groups or changes during the experiments (data not shown).

Control piglets. Table 2 demonstrates that $\mathrm{PaO}_{2}$, base deficit, blood pressure, heart rate, and plasma hypoxanthine were quite stable in the control piglets (group 3) throughout the experiment.

Status after $4 d$. No resuscitated animal later died from the hypoxic injury. The average weight increase was $10-13 \%$ with no differences between the three groups. Blood gases and plasma and CSF hypoxanthine levels were within normal limits with no significant differences between the three groups (data not shown). Hypoxanthine in vitreous humor was $16 \pm 7,15 \pm 5$, and $15 \pm$ $6 \mu \mathrm{mol} / \mathrm{L}$ in group 1,2 , and $3(\mathrm{NS})$, respectively, and urine hypoxanthine/creatinine ratios (12) were $11 \pm 2,9 \pm 6$, and 13 $\pm 8 \mu \mathrm{mol} / \mathrm{mmol}(\mathrm{NS})$.

Morphologic examination. Table 3 summarizes the lesions found in the cerebral cortex and white matter, the cerebellum, and the CA1 hippocampal area. Necrotic neurons could quite easily be identified (Fig. 6).

The brain damage varied considerably, but no significant differences were found between the two groups in any of the examined areas. All animals subjected to hypoxia showed some damage in white matter/cerebral cortex located mainly in the watershed areas between the large cerebral arteries. These lesions varied from small $(\leq 1 \mathrm{~mm})$, incomplete infarcts in white matter to large $(\geq 1 \mathrm{~cm})$, complete infarcts that involved both white matter and cortex. The smallest infarcts, which involved only white matter, were located somewhat more subcortically than those in typical periventricular leukomalacia. Subcortical white matter tended to be more vulnerable than cerebral cortex (Fig.

Table 2. Control piglets (group 3), corresponding variables as in Figures $1-5^{*}$

\begin{tabular}{lccc}
\hline & $0 \mathrm{~min}$ & $120 \mathrm{~min}$ & $300 \mathrm{~min}$ \\
\hline $\mathrm{PaO}_{2}(\mathrm{kPa})$ & $9.7 \pm 1.7$ & $11.4 \pm 1.2$ & $10.6 \pm 1.2$ \\
$\mathrm{BD}(\mathrm{mmol} / \mathrm{L})$ & $-1.5 \pm 3.1$ & $-2.5 \pm 2.5$ & $-0.8 \pm 2.5$ \\
$\mathrm{MAP}(\mathrm{mm} \mathrm{Hg})$ & $52 \pm 7$ & $52 \pm 7$ & $46 \pm 4$ \\
$\mathrm{Heart} \mathrm{rate}$ & $180 \pm 14$ & $190 \pm 32$ & $195 \pm 19$ \\
$\mathrm{P}-\mathrm{Hx}(\mu \mathrm{mol} / \mathrm{L})$ & $29 \pm 8$ & $27 \pm 9$ & $29 \pm 6$ \\
\hline
\end{tabular}

* Control piglets were subjected to the same procedures and samples as group 1 and 2 for $5 \mathrm{~h}$ without hypoxemia. Values shown are mean \pm $\mathrm{SD}$. BD, base deficit; MAP, mean arterial blood pressure; and P-Hx, plasma hypoxanthine concentration.

Table 3. Number of animals with different grades of brain damage*

\begin{tabular}{|c|c|c|c|c|c|c|}
\hline & \multicolumn{2}{|c|}{$\begin{array}{l}\text { White matter- } \\
\text { cerebral cortex }\end{array}$} & \multicolumn{2}{|c|}{ Cerebellum } & \multicolumn{2}{|c|}{$\begin{array}{c}\text { CA1 } \\
\text { hippocampus }\end{array}$} \\
\hline & $\begin{array}{c}\text { Group } \\
1\end{array}$ & $\begin{array}{l}\text { Group } \\
2\end{array}$ & $\underset{1}{\text { Group }}$ & $\begin{array}{c}\text { Group } \\
2\end{array}$ & $\begin{array}{c}\text { Group } \\
1\end{array}$ & $\begin{array}{c}\text { Group } \\
2\end{array}$ \\
\hline Undamaged & 0 & 0 & 2 & 3 & 6 & 5 \\
\hline Grade 1 & 3 & 3 & 3 & 3 & 0 & 2 \\
\hline Grade 2 & 3 & 5 & 3 & 1 & 0 & 1 \\
\hline Grade 3 & 2 & 1 & 0 & 2 & 2 & 1 \\
\hline
\end{tabular}

* Group $1(n=8)$ was reoxygenated with $21 \% \mathrm{O}_{2}$, and group $2(n=$ 9) was reoxygenated with $100 \% \mathrm{O}_{2}$. For definitions, see Materials and Methods. 


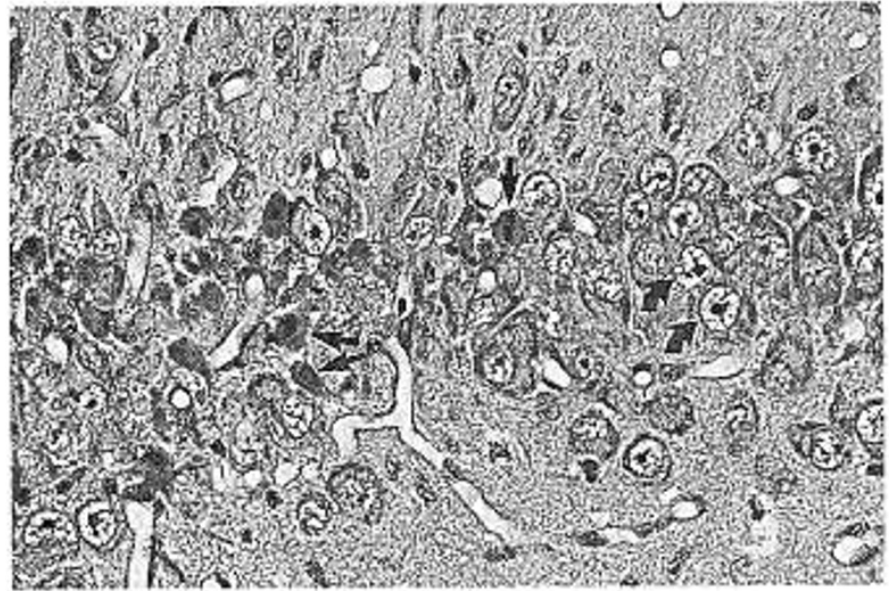

Fig. 6. High power view of grade 1 damage in the CA1 hippocampal area. Necrotic neurons have dark (eosinophilic) cytoplasm and dense pyknotic nuclei (straight arrows), whereas living neurons have large nuclei with prominent nucleoli (curved arrows). (Hematoxylin and eosin; $\times 250$.)

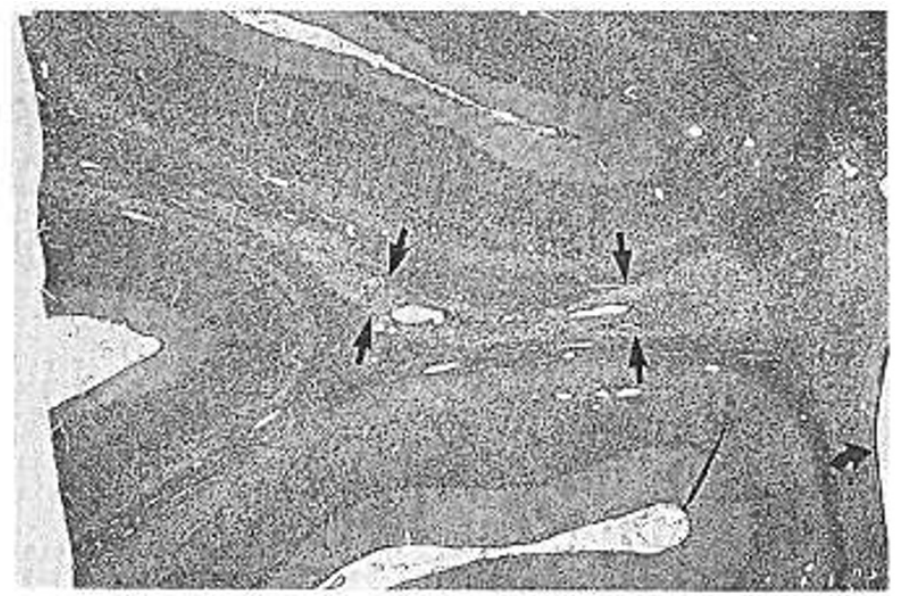

Fig. 7. A grade 2 infarct in subcortical white matter (pale area enclosed by four straight arrows) and normal surrounding cerebral cortex. Curved arrow, lateral ventricle. (Hematoxylin and eosin; $\times 10$.)

7). Most animals also showed some anoxic cerebellar damage with scattered necrotic Purkinje cells. In addition, small cerebellar infarcts were seen in some of the cases, and two animals (group 2) had greater cerebellar infarcts.

Only two animals in group 1 and four animals in group 2 showed selective necrosis of hippocampal pyramidal cells in sector CA1. Three of these cases (one in group 1 and two in group 2) also had some necrotic cells in subiculum. The other hippocampal sectors were normal in all cases.

The three most severely injured animals (two in group 1 and one in group 2) also had small infarcts in the thalamus and basal ganglia. The medulla oblongata was undamaged in all animals. One animal in group 2 showed marked neuronal necrosis in the pontine nuclei. Three animals in group 1 and three animals in group 2 showed a slight pontine neuronal necrosis.

Myelin staining of the basal ganglia gave no indication of selective myelin damage. None of the control piglets showed signs of hypoxic/ischemic brain damage. The hearts of all examined animals were histologically normal.

\section{DISCUSSION}

These results demonstrate that $21 \% \quad \mathrm{O}_{2}$ and $100 \% \mathrm{O}_{2}$ are equally effective for normalizing base deficit, blood pressure, heart rate, and plasma hypoxanthine after severe hypoxemia in newborn pigs and that the extent of the brain damage is similar in the two groups.

The newborn brain is remarkably tolerant to hypoxia, and the degree of hypoxia necessary to induce brain damage is close to lethal (17). Whether or not hypoxemia alone is capable of damaging the brain without superimposed cerebral ischemia has not been settled (18). Because of the marked systemic hypotension, however, there is probably an important ischemic component in this study. Several investigators emphasize the importance of cardiac involvement $(18,19)$ and state that after a purely hypoxic insult severe enough to injure the brain the animal will die from cardiovascular collapse. This was not the case in our study, in which no resuscitated animal later died from hypoxic injury and the hearts were undamaged as assessed by histology.

The pattern of neonatal hypoxic-ischemic brain damage in experimental animals depends on the severity and duration of the asphyctic insult (19). After acute total asphyxia, the main lesions are confined to the brain stem and thalamus. In partial asphyxia, cerebral cortex and cerebellum are most vulnerable. In term human infants, infarcts after neonatal asphyxia are often located in the cerebral cortex and adjacent white matter mainly within the watershed areas between the major cerebral arteries. In more premature infants, infarcts usually occur in the deep (periventricular) white matter, although periventricular leukomalacia is also seen in full-term newborns (18).

The brains of newborn pigs are histologically comparable to those of human infants of 36-38 wk of gestation (20), and the distribution of the infarcts in our study was largely compatible with that described in partial asphyxia in mature experimental animals. However, we found that subcortical white matter was somewhat more vulnerable than the cerebral cortex. The infarcts were located more in the subcortical than the periventricular area, and their distribution in the watershed areas indicates that they represent hypotensive infarcts.

The end point for cessation of hypoxia of a systolic blood pressure of $20 \mathrm{~mm} \mathrm{Hg}$ was chosen instead of a fixed time period because of the great biologic variation in the tolerance of hypoxia. Our aim was a hypoxia severe enough to induce brain damage without too high a mortality. The great variability in brain damage within the groups and the fact that in general the damage was quite moderate make it difficult to detect small differences between the two groups with a relatively small sample size. However, a fixed period of hypoxemia and ischemia by carotid artery ligation results in a great variability in the brain damage as well (21).

The use of anesthetics may have influenced the results obtained. Azaperone and metomidate tend to induce a slight hypotension, and etomidate, a close analog to metomidate, has been reported to give a substantial reduction in cerebral infarct size (22).

The importance of $\mathrm{O}_{2}$ concentrations used in resuscitation has not been extensively studied before. Gerbils subjected to $15 \mathrm{~min}$ of bilateral carotid artery ligation and then given $100 \% \mathrm{O}_{2}$ for 3 $\mathrm{h}$ showed a higher mortality than those breathing room air (23). Neuropathologic examination revealed an increased myelin damage in the oxygen-treated animals (24). Neurons, however, appeared better preserved when given oxygen. In our study, there were no signs of such selective myelin damage. In the same gerbil experiment, if the period of hyperoxia was limited to $30 \mathrm{~min}$, the mortality was no longer increased. In rats, $30 \mathrm{~min}$ of hypoxia, normoxia, or hyperoxia after $15 \mathrm{~min}$ of ischemia all gave the same degree of neuronal damage (25). The duration of hyperoxia in the present experiment was only $20 \mathrm{~min}$. This may have reduced the possibility of finding differences between the two groups, but it was chosen to mimic the clinical situation in which $100 \% \mathrm{O}_{2}$ is often used in the acute phase in the delivery room.

Unanesthetized preterm lambs recovered more quickly after $30 \mathrm{~s}$ of hypoventilation when given $21 \%$ rather than $100 \% \mathrm{O}_{2}$ (26). In critically ill adult patients, $\mathrm{O}_{2}$ consumption was lower 
during hyperoxia than in normoxia, indicating a possible deleterious effect of hyperoxia on metabolism (27).

Since oxygen radicals are thought to be the mediator of reoxygenation injury $(4,11)$, an important question is whether posthypoxic $\mathrm{PaO}_{2}$ has a significant effect on oxygen radical production. Both superoxide production by xanthine oxidase (28) and brain $\mathrm{H}_{2} \mathrm{O}_{2}$ production (29) increase with oxygen tension, but in vivo animal studies of brain ischemia have given conflicting results $(23,25)$. It is possible that sudden normoxic reoxygenation gives near maximal oxygen radical production and that to reduce damage significantly an even more careful or gradual reintroduction of oxygen is necessary (30).

It may also be important to differentiate between transient and ongoing ischemia (31). During ischemia, oxygen supplementation may increase oxygen delivery to the ischemic penumbra so that the injury may be reduced. On the other hand, when circulation is restored to normal, room air may be sufficient, and an increased oxygen supply might theoretically be deleterious. In the clinical situation, however, it may be difficult to determine whether there is any ongoing cerebral ischemia.

$\mathrm{PaO}_{2}$ in the group receiving $21 \% \mathrm{O}_{2}$ had reached baseline levels when the first blood gas was taken after 5 min of reoxygenation and maintained this level thereafter. This indicates that, provided the lungs are healthy, $21 \% \mathrm{O}_{2}$ is sufficient to quickly normalize $\mathrm{PaO}_{2}$. The hyperoxia group had a significantly higher $\mathrm{PaO}_{2}$ even when both groups were given $21 \% \mathrm{O}_{2}$, but the differences were small and only present during the $1 \mathrm{st} h$ of reoxygenation.

Under normal conditions, $\mathrm{PaO}_{2}$ levels achieved with room air will almost fully saturate $\mathrm{Hb}$. However, because acidosis markedly reduces the affinity of $\mathrm{Hb}$ for oxygen, this would not be the case in this study. Calculated oxygen saturations (based on a standard adult human oxygen dissociation curve) in the $21 \% \mathrm{O}_{2}$ group were only about $70 \%$ after 5 and $15 \mathrm{~min}$ of reoxygenation. Despite this, the normalization of the measured parameters were equal in the two groups.

The high hypoxanthine values found in this study indicate that the hypoxic insult to the animals was severe. Mean hypoxanthine levels began to fall immediately after reoxygenation in both groups, whereas base deficit increased during the first $5 \mathrm{~min}$. A slight increase in hypoxanthine at $5 \mathrm{~min}$ was seen in only two animals. A washout effect in which hypoxanthine increased after reoxygenation has been demonstrated for some asphyctic newborns during the first 10-20 min after birth (32). The initial halflife for excess hypoxanthine of 48 and $51 \mathrm{~min}$ is comparable to the half-life of $40 \mathrm{~min}$ found in young pigs (33) and that of 25 min found in fetal sheep (16).

The rates of elimination of hypoxanthine and normalization of metabolic acidosis were equal in the two groups both during the first 20 min when treatment differed and later. This indicates that $21 \% \mathrm{O}_{2}$ relieves tissue hypoxia just as effectively as $100 \%$ $\mathrm{O}_{2}$ in this setting.

All blood samples were taken postductally. The ductus arteriosus in newborn piglets is reported to be functionally closed after $4 \mathrm{~h}$ (34), and postductal blood samples were found to be representative in healthy animals (20). Because of the severe hypoxia, acidosis, and systemic hypotension, this was not necessarily the case in the hypoxemic phase of this experiment. During reoxygenation, however, when the two groups were compared, the high $\mathrm{PaO}_{2}$ and systemic blood pressure make a significant right to left shunt highly unlikely.

There are situations, e.g. in developing countries, in which $100 \% \mathrm{O}_{2}$ is not available for neonatal resuscitation. The present data indicate that resuscitation may be effective even without supplementary oxygen. However, there are important reservations regarding the conclusions drawn from the present study. The first concerns the arterial $\mathrm{O}_{2}$ tensions achieved with room air. The piglets in this study had healthy lungs. In the delivery room, the situation is more complex, but if sufficient ventilation is achieved and there is no meconium aspiration or lung hypoplasia, most newborns can probably be sufficiently oxygenated using less than $100 \% \mathrm{O}_{2}$. Another important reservation is that the animals in this experiment were hypoxic but not hypercarbic. The hypercarbia in perinatal asphyxia may have significant effects on general and cerebral circulation that may affect the outcome of resuscitation. Finally, this study concerns longstanding severe hypoxia where a large part of the brain damage may have been irreversible already before resuscitation. In less severe cases of hypoxia or hypoxia of shorter duration, the situation may be different. Therefore, we cannot conclude whether the two treatments are equally effective in preventing brain damage in these situations. Thus, whether room air is sufficient for the resuscitation of asphyxiated newborns is still not settled. Clinical trials testing this are in progress.

Acknowledgments. The authors thank Roger Ødegaard for skillful technical assistance and Knut Falkvoll for statistical advice.

\section{REFERENCES}

1. Zweier JL 1988 Measurement of superoxide-derived free radicals in the reperfused heart. J Biol Chem 263:1353-1357

2. Braughler JM, Hall ED 1989 Central nervous system trauma and stroke. I. Biochemical considerations for oxygen radical formation and lipid peroxidation. Free Radic Biol Med 6:289-301

3. Rosenberg AA, Murdaugh E, White CW 1989 The role of oxygen free radicals in postasphyxia cerebral hypoperfusion in newborn lambs. Pediatr Res 26:215-219

4. Saugstad OD 1990 Oxygen toxicity in the neonatal period. Acta Paediatr Scand 79:881-892

5. Sinet PM, Heikkila RE, Cohen G 1980 Hydrogen peroxide production by rat brain in vivo. J Neurochem 34:1421-1426

6. Shivakumar BR, Anandatheerthavarada HK, Ravindranath V 1991 Free radical scavenging systems in developing rat brain. Int J Dev Neurosci 9:181185

7. Mavelli I, Mondovi B, Federico R, Rotilio G 1978 Superoxide dismutase activity in developing brain. J Neurochem 31:363-364

8. Kurobe N, Kato K 1991 Sensitive enzyme immunoassay for rat Mn superoxide dismutase: tissue distribution and developmental profiles in the rat central nervous tissue, liver, and kidney. Biomed Res 12:97-103

9. American Heart Association 1986 Standards and guidelines for cardiopulmonary resuscitation and emergency cardiac care. JAMA 255:2841-3044

10. Milner AD 1991 Resuscitation of the newborn. Arch Dis Child 66:66-69

11. Saugstad OD 1988 Hypoxanthine as an indicator of hypoxia: its role in health and disease through free radical production. Pediatr Res 23:143-150

12. Harkness RA 1988 Hypoxanthine, xanthine and uridine in body fluids, indicators of ATP depletion. J Chromatogr 429:255-278

13. Wung WE, Howell SB 1980 Simultaneous liquid chromatography of 5-fluorouracil, uridine, hypoxanthine, xanthine, uric acid, allopurinol and oxypurinol in plasma. Clin Chem 26:1704-1708

14. Simmonds RJ, Harkness RA 1981 High-performance liquid chromatographic methods for base and nucleoside analysis in extracellular fluids and in cells. J Chromatogr 226:369-381

15. Poulsen JP, Øyasæter S, Sanderud J, Rognum TO, Saugstad OD 1990 Hypoxanthine, xanthine, and uric acid concentrations in the cerebrospinal fluid, plasma, and urine of hypoxemic pigs. Pediatr Res 28:477-481

16. Thiringer $K$, Karlsson $K$, Rosèn $K G 1981$ Changes in hypoxanthine and lactate during and after hypoxia in the fetal sheep with chronically-implanted vascular catheters. J Dev Physiol 3:375-385

17. Freeman JM, Nelson KB 1988 Intrapartum asphyxia and cerebral palsy. Pediatrics 82:240-249

18. Vannucci RC 1985 Pathogenesis of perinatal hypoxic-ischemic brain damage. In: Thompson RA, Green JR, Johnsen SD (eds) Perinatal Neurology and Neurosurgery. Spectrum Publications, New York, pp 17-39

19. Myers RE 1972 Two patterns of perinatal brain damage and their conditions of occurrence. Am J Obstet Gynecol 112:246-276

20. Laptook A, Stonestreet BS, Oh W 1982 The effects of different rates of plasmanate infusion upon brain blood flow after asphyxia and hypotension in newborn piglets. J Pediatr 100:791-796

21. LeBlanc MH, Farias LA, Markov AK, Evans OB, Smith B, Smith EE, Brown EG 1991 Fructose-1,6-diphosphate, when given five minutes after injury, does not ameliorate hypoxic ischemic injury to the central nervous system in the newborn pig. Biol Neonate 59:98-108

22. Sternau LL, Lust WD, Ricci AJ, Ratcheson R 1989 Role for gamma-aminobutyric acid in selective vulnerability in gerbils. Stroke 20:281-287

23. Mickel HS, Vaishnav YN, Kempski O, von Lubitz D, Weiss JF, Feuerstein G 1987 Breathing $100 \%$ oxygen after global brain ischemia in Mongolian gerbils results in increased lipid peroxidation and increased mortality. Stroke $18: 426-430$

24. Mickel HS, Kempski O, Feuerstein G, Parisi JE, Webster HD 1990 Prominent white matter lesions develop in Mongolian gerbils treated with $100 \%$ normobaric oxygen after global brain ischemia. Acta Neuropathol 79:465-472

25. Agardh C-D, Zhang H, Smith M-L, Siesjö BK 1991 Free radical production 
and ischemic brain damage: influence of postischemic oxygen tension. Int $\mathrm{J}$ Dev Neurosci 9:127-138

26. Hutchison AA 1987 Recovery from hypopnea in preterm lambs: effects of breathing air or oxygen. Pediatr Pulmonol 3:317-323

27. Reinhart K, Bloos F, König F, Bredle D, Hannemann L 1991 Reversible decrease of oxygen consumption by hyperoxia. Chest 99:690-694

28. Fridovich I 1985 Xanthine oxidase. In: Greenwald RA (ed) Handbook of Methods for Oxygen Radical Research. CRC Press, Boca Raton, FL, pp $51-54$

29. Yusa T, Beckman JS, Crapo JD, Freeman BA 1982 Hyperoxia increases $\mathrm{H}_{2} \mathrm{O}_{2}$ production by brain in vivo. J Appl Physiol 63:353-358

30. Perry MA, Wadhwa SS 1988 Gradual reintroduction of oxygen reduces reperfusion injury in cat stomach. Am J Physiol 254:G366-G372
31. Mickel HS 1990 Effect of hyperoxia differs during ischemia and reperfusion. Stroke 21:1641-1642

32. Bratteby L-E, Swanström S 1982 Hypoxanthine concentration in plasma during the first two hours after birth in normal and asphyxiated infants. Pediatr Res 16:152-155

33. Saugstad OD, Aasen AO, Hetland $\emptyset 1978$ Plasma hypoxanthine levels in pigs during acute hypoxemia. A correlation between lactate and base deficit concentrations. Eur Surg Res 10:314-321

34. Haworth SG, Hislop AA 1981 Adaptation of the pulmonary circulation to extra-uterine life in the pig and its relevance to the human infant. Cardiovasc Res 15:108-119 